Article

\title{
Primary Structure and Graphite Nodules in Thin-Walled High-Nickel Ductile Iron Castings
}

\author{
Marcin Górny ${ }^{1, *}$ (D) , Magdalena Kawalec ${ }^{1}$, Gabriela Sikora ${ }^{1}$, Ewa Olejnik ${ }^{1}$ and Hugo Lopez ${ }^{2}$ \\ 1 Faculty of Foundry Engineering, Department of Engineering of Cast Alloys and Composites, \\ AGH University of Science and Technology, St. Reymonta 23, 30-059 Cracow, Poland; \\ kawalec@agh.edu.pl (M.K.); gsikora@agh.edu.pl (G.S.); eolejnik@agh.edu.pl (E.O.) \\ 2 Materials Department, University of Wisconsin-Milwaukee, 3200 N. Cramer Street, Milwaukee, \\ WI 53211, USA; hlopez@uwm.edu \\ * Correspondence: mgorny@agh.edu.pl; Tel.: +48-12-6172731
}

Received: 27 July 2018; Accepted: 15 August 2018; Published: 17 August 2018

\begin{abstract}
This paper considers the most important quality factors in processing spheroidal graphite cast iron; namely, primary grains and graphite nodules in thin-walled ductile iron castings (TWDI). In the present study, the effect of grain refinement (by means of $\mathrm{Ti}, \mathrm{Nb}$ and $\mathrm{Zr}$ ) and of the holding time after spheroidization and inoculation on effecting the primary grains and eutectic structure in TWDI castings was investigated. Moreover, metallographic examinations (including electron backscattering diffraction, EBSD) were carried out to reveal the macro- and micro-structural features during the primary and eutectic solidification of the cast iron. EBSD results indicate that, within a single dendritic grain, there are numerous boundaries that split the grain into numerous smaller areas. In particular, it is found that the graphite nodules are in contact with the boundaries inside the primary dendritic grain. In turn, crystallization of highly branched dendrites is observed, which seems to "push" the graphite nodules into the interdendritic regions during their growth. The present work investigates the dominant mechanism that gives rise to the primary spheroidal graphite cast iron (SGI) structure. In addition, this work shows that the melt quality is closely associated with the resultant morphology and number of austenite dendrites, graphite nodules, and matrix structure.
\end{abstract}

Keywords: solidification; primary austenite grain; eutectic grain; graphite; ductile iron

\section{Introduction}

Spheroidal graphite cast iron (SGI) belongs to a group of important engineering materials due to its excellent mechanical properties and significant savings in cost and weight (as compared to equivalent steel and aluminum alloys) [1-3]. This, in combination with excellent castability and machinability, including a less-sensitive microstructure to cooling rates (vs. flake graphite cast iron, FGI) makes it the base material for the production of "high tech" austempered ductile iron (ADI). ADI contains graphite which contributes directly to the lubrication of wearing surfaces and provides reservoirs to accommodate and hold lubricants.

The excellent combination of properties found in thin-walled ductile iron castings (TWDI), including thin-walled austempered and alloyed iron (e.g., ferritic and austenitic SGI), make them highly viable materials to be employed as substitutes for steel castings and forgings in various engineering applications. Hence, SGI should be considered as an ideal material for the manufacture of light castings possessing good mechanical strength and ductility, the cost of which is relatively low. From the point of view of economics and ecology, thin-walled iron castings easily compete with "light" aluminum alloy castings in terms of mechanical properties [1,4-7]. 
In SGI castings, the primary grains (austenite dendrites) and graphite nodules are quality factors which reflect the physical-chemical state of liquid metal at a given cooling rate. In general, increasing the volumetric density of primary grains leads to reduced shrinkage porosity, improved castability, increased pressure tightness, and improved mechanical properties [8,9]. In contrast, increasing the number of graphite nodules leads to a reduction in the chilling tendency of cast iron, an increase in the pre-shrinkage expansion and a reduction in segregation [10-14].

The complexity of the problem of graphite crystallization in cast iron has recently been reviewed in the literature [15-17]. The solidification of SGI is a subject of appreciable computer modeling programs described in the literature [18-24]. The latest approach is related to the use of multiphase cellular automaton models. In this case, the evolution of the microstructure of spheroidal graphite cast iron during its solidification process (hypoeutectic, eutectic, or hypereutectic composition) has been carried out by employing both, the dendritic austenite and the spheroidal graphite growth models. In addition, a solute balance method including decentered square algorithms has been employed to simulate austenite dendrite growth with different crystallographic orientations. This has been shown by the simulation of $\mathrm{Wu}$ et al. [24], after eutectic graphite precipitation from the liquid, and envelopment by the austenite phase. In their work, the graphite nodules are mainly located on dendritic grain boundaries. The interaction between graphite nodules and austenite dendrites is controlled by a similar mechanism to that controlling particle engulfment and pushing (PEP) as reported by Ruxanda et al. [25]. In addition, in modeling SGI natural forced convection is not considered in the solidification process. In fact, the graphite nodules can change their location (e.g., as a result of the turbulence in the liquid metal during mold filling and the occurrence of hot spots). The numerical models for the nucleation and growth processes in SGI reported in the literature do not take into account the dendrite morphology from the point of view of interactions between the dendrite branches and the graphite nodules. This is very important as it is directly related to the structural homogeneity and optimization of the mechanical properties.

One of the important factors affecting the austenite dendrites and graphite nodules is related to primary grain refinement and inoculation treatment (to increase the number of graphite nodules). In general, it can be stated that all high-quality alloys are grain refined or inoculated. Grain refinement, inoculation and cooling rate control the exhibited austenite dendrite including the eutectic grain structure. Moreover, the matrix microstructure depends on the conditions under which the eutectoid reaction occurs. Among the variables that influence the eutectoid reaction are the chemical composition, the cooling rate through the eutectoid temperature range, and the eutectic grain structure. According to Fraś [26], grain refinement/inoculation can be defined as the treatment in which certain substances (called grain refinements or inoculants) are introduced to the melt to radically enhance the number of grains in single-phase alloys. In addition, in alloys crystallizing through a eutectic reaction, they modify the density of eutectic grains as well as their morphology. A common feature of the grain refinement process is the fading effect overtime from the instant of addition to the liquid metal. This is why grain refinement differs from micro alloying as the effects associated with alloying are independent of time [27].

In this study, a high Ni-alloyed (>18\%) cast iron, which does not undergo a eutectoid transformation (i.e., austenitic metallic matrix) was investigated. Ni has a similar electron structure to $\mathrm{Fe}(\gamma)$ and, during solidification, both the $\mathrm{Fe}(\gamma)$ and Ni have a primary phase which consists of a face-centered cubic (FCC) crystal structure. High Ni-alloyed cast iron is also an excellent modeling alloy where one can examine the crystallization process of both the primary and eutectic structures. In addition, high Ni-alloyed SGI (Ni-Resist ductile iron) with an austenitic matrix possesses high corrosion resistance, pressure seal and creep resistance, and good load-bearing properties. It is also non-magnetic when containing low levels of chromium, and it is highly castable and machinable. The tensile strength is within a range of 380-550 MPa, and its elongation might exceed $45 \%$.

The published literature provides limited data on the formation of the primary structure in SGI [28-35]. This is key to understanding the microstructural evolution and, ultimately, the optimization 
of mechanical and other properties. In this work, an investigation into the changes in the primary dendrites and graphite nodules in thin-walled SGI with an austenitic metallic matrix as a result of liquid treatment. In particular, this work considers the relationships between holding time after the spheroidization and inoculation processes, including the resultant micro- and macro-structure formation in thin-walled SGI castings. Finally, in this work, a mechanism is proposed that accounts for the primary structure and for the eutectic in high-nickel TWDI with an austenitic metallic matrix.

\section{Materials and Methods}

The experimental melts were produced using an electrical induction furnace IMSK 10 (Inducal Göllingen, Dresden, Germany) of intermediate frequency with a 15-kg-capacity crucible (Mammut, Puschwitz, Germany). The furnace charge consisted of Sorelmetal, technically pure silica, Fe-Mn, steel scrap, and pure nickel $\left(99.99 \% \mathrm{Ni}\right.$, Stanchem, Niemce, Poland). Melting was carried out at $1490{ }^{\circ} \mathrm{C}$, with the liquid metal held at this temperature for $2 \mathrm{~min}$. This was followed by spheroidization and inoculation using the bell method. After dissolution of both, the master alloy and the inoculant in time intervals of 40,150,300, and $600 \mathrm{~s}$, the liquid metal was poured into sand molds. As-cast test blocks were obtained by following the ASTM A 536-84 standard with plate cross section thicknesses, $t=5 \mathrm{~mm}$. A Fe-Si-Mg (6\% Mg, Elkem, Norway) master alloy was used for the spheroidization process and a Fe-Si alloy (75\% Si, $0.75-1.25 \% \mathrm{Ca}, 0.75-1.25 \% \mathrm{Ba}, 0.75-1.25 \%$ Al, Elkem, Norway) in an amount of $0.6 \mathrm{wt} . \%$ for inoculation. Four series of melts were produced, the first one without alloying additions. In the second series of melts, Fe-Ti was introduced along with the spheroidization process. In the third and fourth series of melts, $\mathrm{Fe}-\mathrm{Zr}$ and $\mathrm{Fe}-\mathrm{Nb}$ (Stanchem, Niemce, Poland) were added, respectively. The addition of $\mathrm{Ti}, \mathrm{Zr}$, and $\mathrm{Nb}$ was set to attain a $0.1 \%$ of the alloying elements. The pouring temperature was approximately $1400{ }^{\circ} \mathrm{C}$. Samples for metallographic examinations were taken from the bottom part of the ingots and the macrostructure was revealed by immersion in a Stead reagent for $30 \mathrm{~s}$. Cleaning in a special solution was used to remove the adhered $\mathrm{Cu}$ and the austenite grain structure was revealed by Electron Back Scattering Diffraction (EBSD) in a Jeol JSM-7200 (JEOL, Tokyo, Japan) scanning electron microscope.

\section{Results}

Table 1 shows the composition of the experimental cast irons. The carbon equivalent (CE) of the experimental high-nickel cast irons was estimated using Equation (1) [36]:

$$
C E=C+0.33 \cdot \mathrm{Si}+0.047 \cdot \mathrm{Ni}-(0.0055 \cdot \mathrm{Ni} \cdot \mathrm{Si})
$$

Taking into account the chemical composition (Table 1), it is found that the CE corresponds to cast irons of hypoeutectic composition for all of the investigated alloys ( $C E=4.09,3.97,4.07$, and 4.11 for Series I, II, III, and IV, respectively).

Table 1. Chemical composition of the investigated cast irons.

\begin{tabular}{ccccccccccc}
\hline \multirow{2}{*}{ Series No. } & \multicolumn{10}{c}{ Element, wt.\% } \\
\cline { 2 - 11 } & $\mathbf{C}$ & $\mathbf{S i}$ & $\mathbf{N i}$ & $\mathbf{M g}$ & $\mathbf{M n}$ & $\mathbf{S}$ & $\mathbf{T i}$ & $\mathbf{N b}$ & $\mathbf{Z r}$ & $\mathbf{F e}$ \\
\hline I & 2.55 & 2.15 & 23.50 & 0.050 & 0.85 & 0.010 & 0.00 & 0.00 & 0.00 & Balance \\
II & 2.43 & 2.28 & 22.84 & 0.037 & 0.81 & 0.008 & 0.13 & 0.00 & 0.00 & Balance \\
III & 2.50 & 2.10 & 25.85 & 0.040 & 0.98 & 0.020 & 0.00 & 0.00 & 0.10 & Balance \\
IV & 2.51 & 2.05 & 24.66 & 0.042 & 1.00 & 0.003 & 0.00 & 0.11 & 0.00 & Balance \\
\hline
\end{tabular}

\subsection{Microstructure}

Figure 1 shows the high-nickel cast iron microstructures as a function of the holding time after spheroidization and inoculation treatments. 


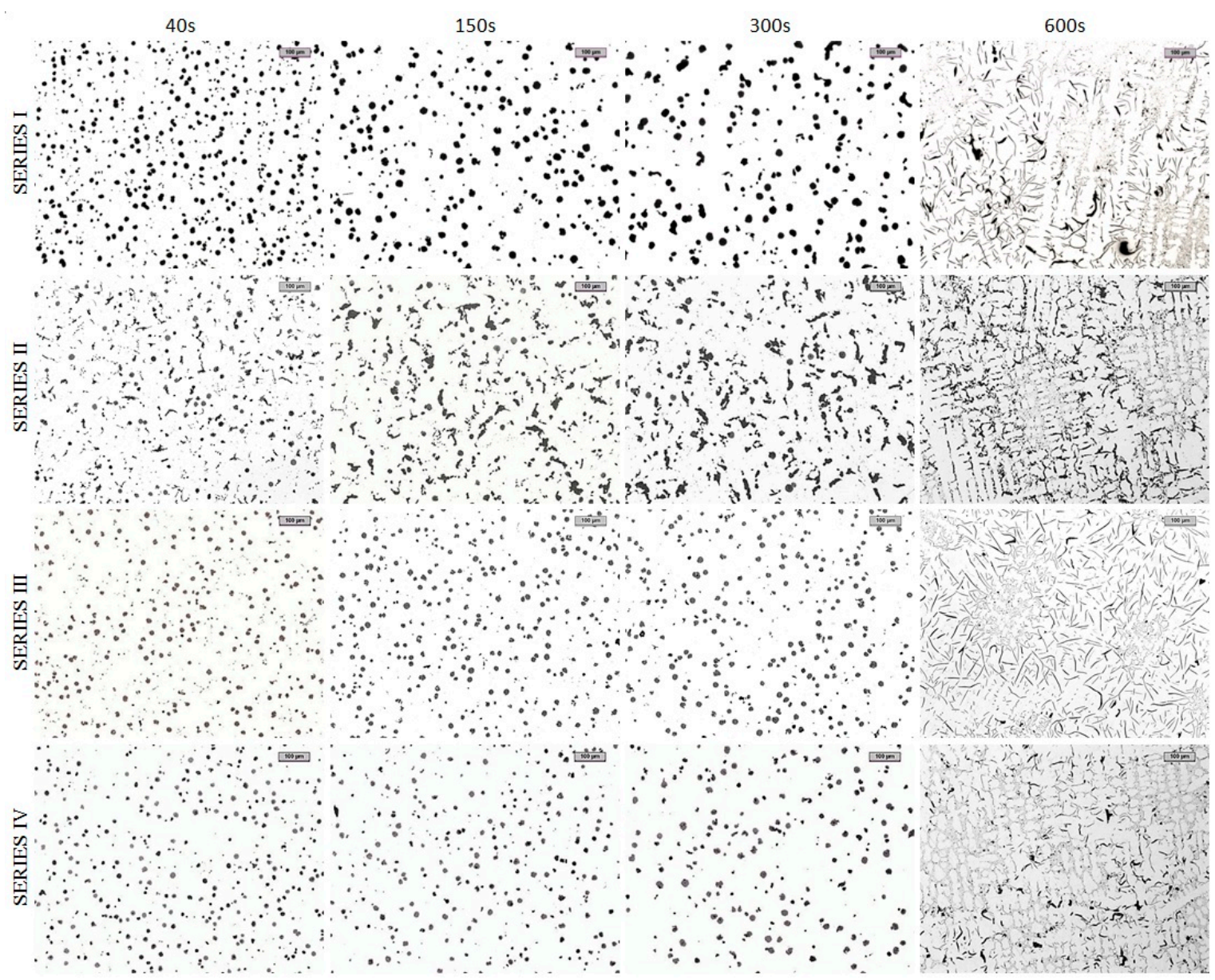

Figure 1. Microstructures in thin-walled castings $(t=5 \mathrm{~mm})$ attained at various holding times of the liquid metal after spheroidization and inoculation. Magnification: $100 \times$ (non-etched samples).

In the case of Series I, III, and IV (Figure 1), graphite nodules are present in the microstructures up to $300 \mathrm{~s}$, whereas a complete transformation of nodular graphite into the D-type graphite (interdendritic) is visible only after $600 \mathrm{~s}$. Due to the adverse impact of high cooling rates on the formation of compacted graphite, thin-walled compacted graphite iron castings (TWCGI) are difficult to produce $[37,38]$. In this connection, standard foundry practice and good production discipline are not enough to maintain the desired microstructures under high cooling rates without the use of both, anti-nodularization elements (such as Ti) and a control of the cooling rate at the start of solidification [39]. From the microstructures Series II shown in Figure 1, it is found that the addition of Ti has a very strong compacting effect. Immediately after the spheroidization and grain refinement treatments (with the addition of $\mathrm{Fe}-\mathrm{Ti}$ ), the fraction of compacted graphite is $50 \%$. At increasing times, the fraction of the compacted graphite increases to $65 \%$ (after a holding time of $150 \mathrm{~s}$ ) and $80 \%$ (holding time, $300 \mathrm{~s})$, respectively.

After $600 \mathrm{~s}$, there is a transformation of compacted graphite into graphite D (as was the case in Series I, III, and IV). The presence of titanium in spheroidal graphite cast iron is found to be very harmful due to: (1) the strong compacting effect on the graphite; and (2) the solidification of the titanium carbides and titanium carbonitrides in the form of faceted crystals. The presence of these carbides or carbonitrides can strongly reduce the machining tool life. This is particularly important in the production of castings that require extensive machining (such as cylinder blocks and heads) where titanium additions are not permissible and should be kept as low as possible [39]. Hard Ti-rich inclusions can also nucleate cracks during cyclic stressing and, thus, reduce the fatigue life [40]. 
Fading of the spheroidization and inoculation effects is accompanied by a change in the number of eutectic grains as well as in the eutectic morphology. The change in the number of graphite nodules as a function of the holding time of the liquid metal from the inoculation process is shown in Figure 2.

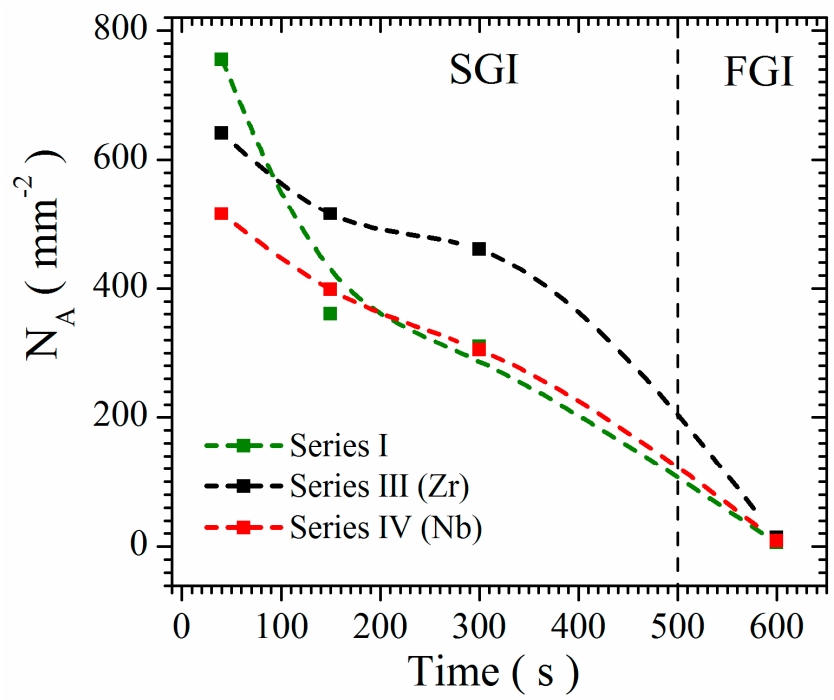

Figure 2. Influence of holding time of the liquid metal after spheroidization and inoculation on the graphite nodule count.

In Figure 2, it is found the highest change in graphite nodule count occurs during the first period of fading (150 s after spheroidization and inoculation), confirming prior research [41]. The main effect of the inoculation process is an increase in the graphite nucleation potential. Each graphite nucleus in SGI creates a single eutectic grain, which can be treated as a measure of the graphite nucleation potential. Right after the dissolution of the inoculant, the so-called super-inoculated state occurs, which is characterized by the highest eutectic grain density.

\subsection{Macrostructure}

Figure 3 shows the primary austenite grains in the macrostructures of the cast iron as a function of holding time after spheroidization and inoculation.

In Figure 3 it is observed that the austenite grains in Series I, III, and IV are of columnar morphology. Notice that austenite dendrites commonly nucleate on the mold walls and grow until they impinge in the central part of the casting because the solidification rate is higher, and the heat flows significantly along the wall thickness from the center to the edge. After the impingement of the dendrites, growth continues by dendrite arm coarsening. From metallographic determinations (Series I), it is found that the thickness of the dendrites (measured as the width at its half-height) increases with time as: $796 \pm 135 \mu \mathrm{m}(40 \mathrm{~s}) \rightarrow 854 \pm 137 \mu \mathrm{m}(150 \mathrm{~s}) \rightarrow 1077 \pm 112 \mu \mathrm{m}(300 \mathrm{~s}) \rightarrow$ $1308 \pm 279 \mu \mathrm{m}(600 \mathrm{~s})$. This is because the holding time of the liquid metal removes the existing heterogeneous austenite nuclei or makes them less effective, giving rise to a reduced number of nuclei. A high cooling rate close to $20 \mathrm{~K} / \mathrm{s}$, typical of thin-walled castings (with a wall thickness of $5 \mathrm{~mm}$ ), undoubtedly favors columnar grains.

In the second series, where Fe-Ti was employed, the transformation of exogenous to endogenous crystallization occurs after a relatively short time of only $300 \mathrm{~s}$. A refining effect of titanium on the primary austenite is likely since carbides, nitrides, and carbonitrides can act as nucleation substrates for austenite [42]. In the case of titanium, a refining effect is also plausible since, at $\{001\} \mathrm{TiC} / /\{110\}$ austenite crystal faces and along the $<110>\mathrm{TiC} / /<111>$ austenite directions, the atom-spacing difference is rather large, $1.5 \%$ [42]. Other elements besides $\mathrm{Ti}$ (like $\mathrm{Zr}$ or $\mathrm{Nb}$ ) can give rise to carbides, nitrides, or carbonitrides, which are effective nuclei for austenite formation [42]. In this work, it is 
found that the addition of zirconium and niobium did not change the morphology of the austenite dendrites. In addition, the time elapsed after the liquid treatment does not change crystallization mode of the primary grains.
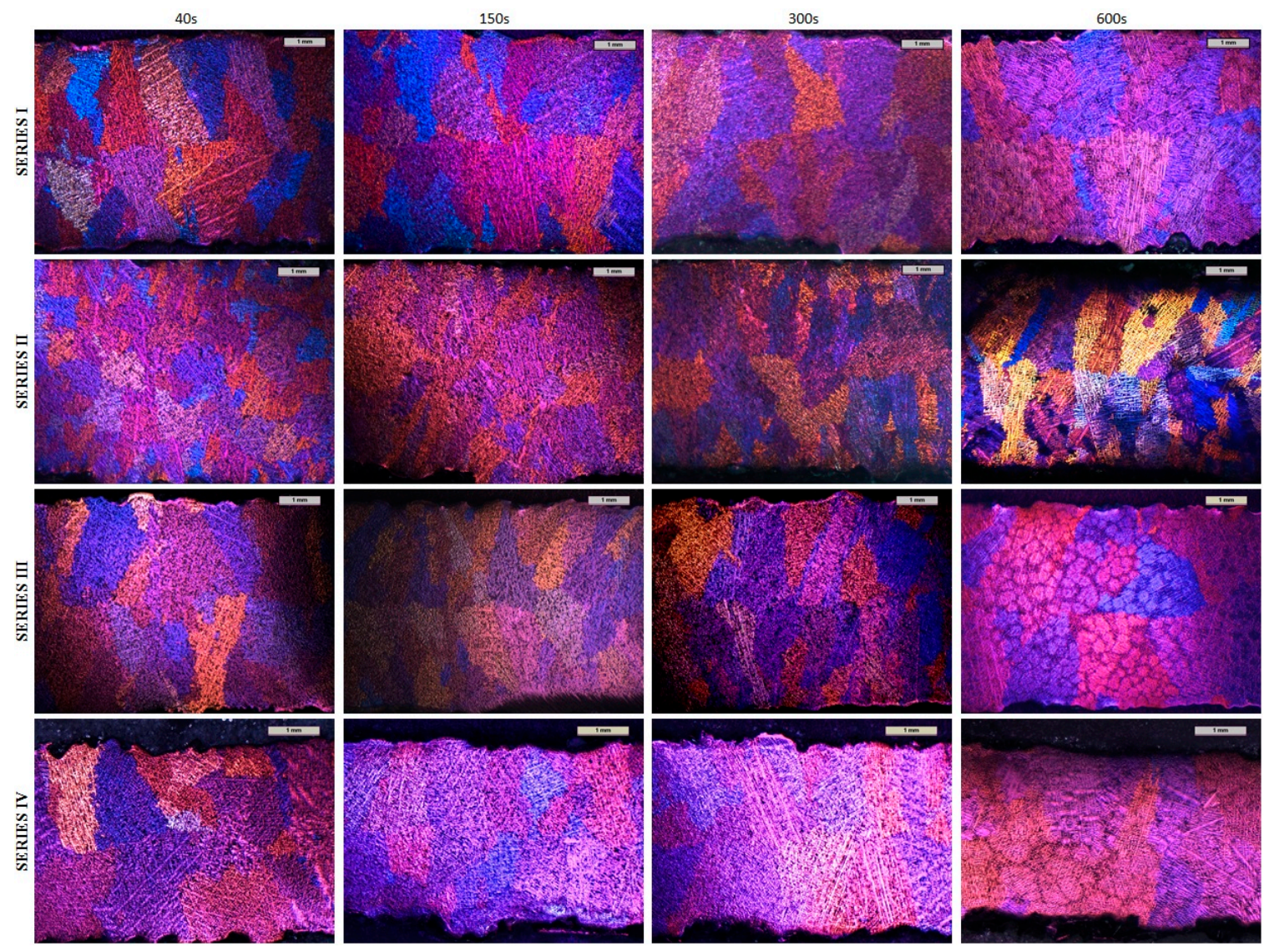

Figure 3. Macrostructures in thin-walled castings $(t=5 \mathrm{~mm})$ obtained at different holding times of liquid metal after spheroidization and inoculation: Magnification: $8 \times$ (etched samples; polarized light).

\section{Discussion}

The solidification of the hypoeutectic and eutectic Fe-C alloys (see Figure 4) starts with the nucleation and growth of the austenite dendrites [43].

In the case of alloys with hypereutectic composition when the temperature decreases below the liquidus, graphite nodules are nucleated and then grow freely in the liquid [44]. Then, austenite dendrites begin to nucleate and grow as soon as the solidification path intersects the metastable line corresponding to the austenite liquidus (extrapolated) (see Figure 4). Spheroidal graphite cast iron has an asymmetric eutectic coupled zone, which is why the austenite dendrites play an important role in shaping the structure of cast iron, as they are present in the structure regardless of whether we consider the hypoeutectic, eutectic, or hypereutectic composition of cast iron (Figure 4).

In general, each primary grain is composed of one dendrite and has the same crystallographic orientation all over it. Yeung et al. [45] investigated the morphology of the solidified structures of thin-section ductile iron castings by color metallography. They found that the austenite dendrites usually nucleate on the mold walls in thin-walled castings [45]. Yeung et al. [45] proposed a model in which the dendrites are thin (without branching) and long in shape growing normal to the surface of the castings towards the center and along the wall thickness. Outlining the austenite dendrites on the metallographic structure is not trivial [46]; this topic is particularly thorny in cast iron due to the presence of a eutectoid reaction which prevents disclosing the primary dendrites of the austenite 
grains. Boeri and Sikora [47] disclosed the austenite dendrite grains by austempering the cast iron after solidification without cooling to room temperature (direct austempering after solidification, DAAS). Rivera et al. [30] indicated that the solidification of spheroidal graphite cast irons is dominated by the growth of austenite dendrites developing a grain pattern similar to that found in most metallic alloys.

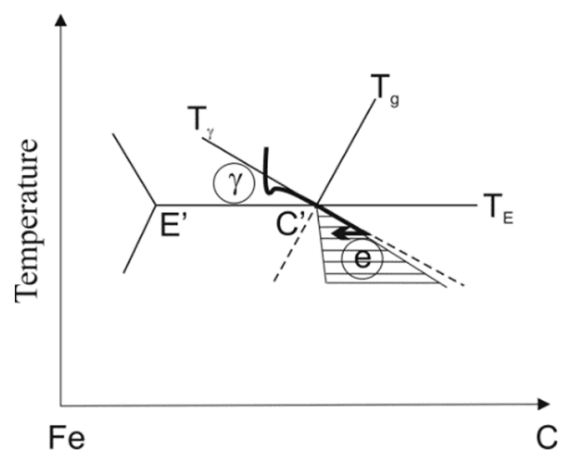

(a)

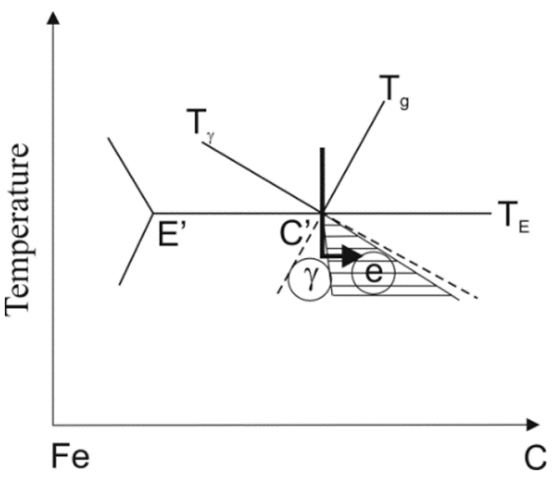

(b)

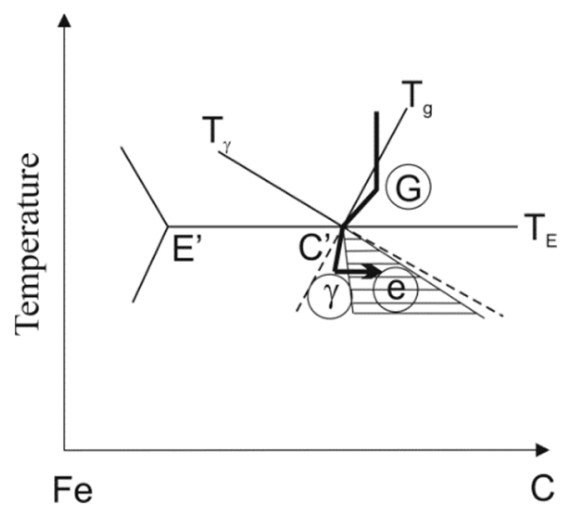

(c)

Figure 4. Solidification "path" of: hypoeutectic (a); eutectic (b); and hypereutectic (c) cast iron. $\gamma$, austenite dendrites; $\mathrm{G}$, primary graphite; e, eutectic, $\mathrm{E}^{\prime}$, carbon content in austenite at temperature $\mathrm{T}_{\mathrm{E}} ; \mathrm{C}^{\prime}$, carbon content in graphite eutectic; $\mathrm{T}_{\gamma}$, equilibrium temperatures for solidifying austenite dendrites; $\mathrm{T}_{\mathrm{g}}$, equilibrium temperatures for solidifying primary graphite; $\mathrm{T}_{\mathrm{E}}$, graphite eutectic equilibrium temperature.

According to Rivera et al. [30], spheroidal graphite particles are enveloped by an austenite layer soon after they make contact with the growing austenite dendrites. Further growth is controlled by carbon diffusion from the melt to the graphite nodules through the austenite envelope. As the dendrites grow, they contact each other, defining the grain size. As a result of this growth mechanism, each austenite grain contains a large number of graphite nodules inside. Unfortunately, there is little space devoted to the problem of the influence of austenite dendrites with graphite nodules in the literature. In most cases, the statement is used that the graphite nodules are enveloped by an austenite layer and further growth occurs as a result of carbon diffusion through its shell. The influence of the cooling rate, temperature gradient, and chemical composition on the degree of the austenite dendrite branching and, consequently, the structural homogeneity is usually omitted.

In the literature, one can also find discrepancies related to "eutectic grains" in spheroidal graphite cast iron (SGI). According to Fras et al. [44], each graphite nodule represents one eutectic grain, while, according to Stefanescu [46], the eutectic grain cannot be defined in ductile iron. According to the work of Stefanescu [46], several nodules grow in contact with the primary austenite, and the eutectic austenite cannot be distinguished from the primary austenite. This is probably due to the rapid growth of the austenite dendrites, which "engulf" the graphite nodules preventing austenite nucleation on 
them. Considering the crystallographic orientation and minimal mismatch between the (0001) plane of graphite and the (111) plane of austenite, it is expected that graphite can be an effective substrate for austenite nucleation [42].

The problem of austenite nucleation on graphite nodules has been described by Zhou [42], who suggested the formation of an austenite halo around graphite. Using color metallography, Zhou [42] stated that the nucleation of austenite occurs in several sites on the graphite nodule. It is not clear if this model reflects reality. If so, crystallographic orientation conditions for the austenite arising from each nucleus would be determinant. Hence, to further elucidate the nucleation aspects, microstructural studies were carried out using a scanning electron microscope with an EBSD system. Figure 5 shows the microstructure of spheroidal graphite cast iron with an austenitic metallic matrix.

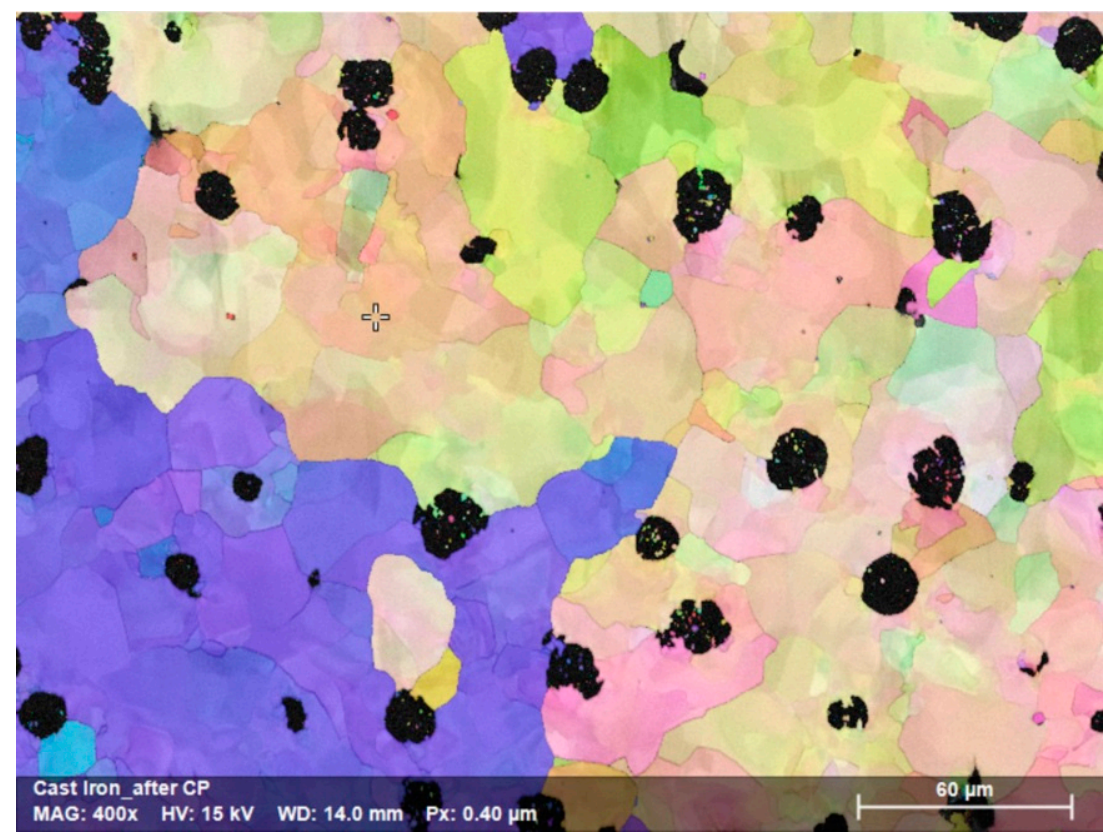

Figure 5. EBSD map for high-nickel SGI (Series I, time $150 \mathrm{~s}$ ) with an austenitic matrix.

The micrograph in Figure 5 shows two columnar austenite dendrite grains (Grain I, violet color; Grain II, yellow/greenish/pink). Notice that there are boundaries inside each grain that divide these primary grains into numerous smaller areas. These in turn most likely resulted from the crystallization of highly branched dendrites. In this figure, it is apparent that each graphite nodule is in contact with a boundary inside these primary grains. In turn, this suggests that graphite nodules nucleate in the inter-interdendritic spaces with the dendrites pushing them during their growth. A possible pushing mechanism of graphite spheroids was also suggested by Ruxanda et al. [25]. This is also evidenced by the uneven distribution of the graphite nodules (Figure 1) even though graphite alignment can be induced as reported by Gorny et al. [1].

Graphite alignment plays a greater role in TWDI castings than in thicker sections. Under stress, this weak graphite alignment may induce premature failure of the casting [1]. The movement of graphite nodules in the liquid metal also occurs in some cases as a result of graphite segregation (flotation), causing structural heterogeneity [1]. Such behavior can be a result of a long crystallization time, for example, where graphite nodules of large sizes move towards the upper surface of the casting due to Stokes's law. Figure 5 shows that the austenite color does not differ at all from the one around the graphite nodules and it can only mean a slight deviation of the dendrite branches. In turn, from this outcome, there is no support for the model proposed by Zhou [42] for the nucleation of austenite on the graphite nodules in thin-walled castings. 
The interaction of the dendrite-graphite nodules can be analogous to metal matrix composites (MMC), for example, with silicon carbide particles as a reinforcing phase. In most MMC (especially those in-situ), the particles are pushed to the grain boundaries. The main factors responsible for this behavior are the difference between the thermal conductivities of particles and metal, the buildup of volume fraction of particles at the interface, and the morphological instability of the interface induced by the particles [48]. In addition, particles such as SiC can also be pushed to the interdendritic regions because, in fact, the dendrites are highly branched (as shown in Figure 5). The results of this study support the proposals of the authors about the crystallization mechanism in thin-walled ductile iron castings (schematically shown in Figure 6).
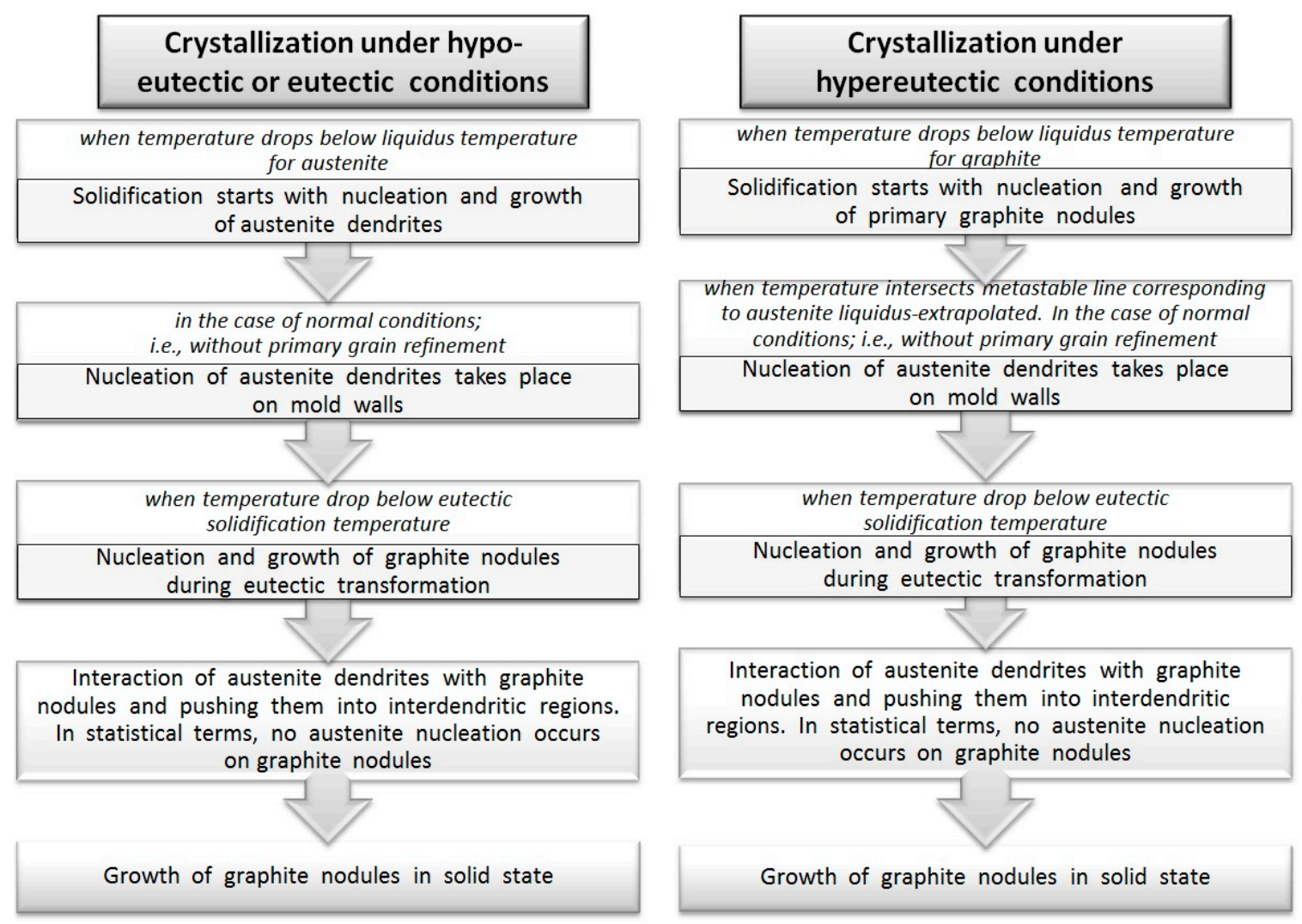

Figure 6. Crystallization mechanism in high-nickel TWDI.

The proposed crystallization mechanism (Figure 6) results from an analysis of the micro- and macro-structures of high-nickel SGI with an austenitic matrix by means of color metallography and the EBSD technique. The occurrence of graphite in the interdendritic spaces contributes to the inhomogeneity of the structure. This is particularly evident in thin-walled castings cooled at high speeds. The morphology of the austenite dendrites depends on various technological factors; mainly, the mentioned cooling rate, temperature gradient, and chemical composition. Generally, it can be stated that the process of crystallization of austenite dendrites and graphite nodules is of the greatest importance as they determine the final structure and, thus, the useful properties of the castings. Here, carbon diffusion in the solid state for graphite growth also plays an important role, since, after the eutectic transformation, the degree of graphitization is only about $40 \%$.

\section{Conclusions}

The following conclusions can be drawn from the present experimental investigation: 
- The fading effects of grain refinement and inoculation of the primary structure and eutectic are accompanied by changes in the morphology and number of austenite dendrites and eutectic grains.

- The refining process of the primary and eutectic grains is unstable and requires strict metallurgical control.

- Under non-refined conditions, the solidification of SGI in thin-walled castings is dominated by the presence of large (columnar) austenite primary grains.

- Additions of Ti to the melt (Series II) can modify the primary structure in thin-walled castings, resulting in the transformation of the exogenous to endogenous crystallization of the austenite dendrites.

- Additions of $\mathrm{Zr}$ and $\mathrm{Nb}$ to the melt (Series III and IV) does not modify the primary structure in thin-walled castings as in the case of Ti.

- $\quad$ The EBSD study shows that there are numerous boundaries dividing the grain into many small areas within a single dendritic grain. It is found that the graphite nodules are in contact with the boundaries developed inside the primary grains. This most likely resulted from crystallization of highly branched dendrites that pushed the graphite nodules into the interdendritic regions during their growth. This in turn strongly affects the graphite nodule distribution, and it may also contribute to the occurrence of graphite alignment.

Author Contributions: Conceptualization, M.G., M.K., E.O. and H.L.; Methodology, G.S.; Investigation, M.G. and G.S.; Writing-Original Draft Preparation, M.G.; and Writing-Review and Editing, M.G., M.K. and H.L.

Funding: This research was funded by Polish National Science Centre grant number 2013/09/B/ST8/00210.

Acknowledgments: This research was conducted within Polish National Science Centre grant number 2013/09/B/ST8/00210.

Conflicts of Interest: The authors declare no conflict of interest.

\section{References}

1. Górny, M.; Stefanescu, D.M. Thin-wall ductile iron castings. In Cast Iron Science and Technology; Stefanescu, D.M., Ed.; ASM Handbook; ASM International: Columbus, OH, USA, 2017; Volume 1A, pp. 617-628, ISBN 978-1-62708-133-7.

2. Loper, C.R. Cast Irons-Essential Alloys for the Future. In Proceedings of the 65th World Foundry Congress, Gyeongju, Korea, 20-24 October 2002; pp. 169-179.

3. Stefanescu, D.M.; Ruxanda, R. Lightweight Iron Castings-Can They Replace Aluminum Castings. In Proceedings of the 65th World Foundry Congress, Gyeongju, Korea, 20-24 October 2002; pp. 71-77.

4. Stefanescu, D.M.; Dix, L.P.; Ruxanda, R.E.; Corbitt-Coburn, C.; Piwonka, T.S. Tensile Properties of Thin Wall Ductile Iron. AFS Trans. 2002, 110, 1149-1161.

5. Ruxanda, R.; Stefanescu, D.M.; Piwonka, T.S. Microstructure Characterization of Ductile Thin Wall Iron Castings. AFS Trans. 2002, 110, 1131-1147.

6. Dix, L.P.; Ruxanda, R.; Torrance, J.; Fukumoto, M.; Stefanescu, D.M. Static Mechanical Properties of Ferritic and Pearlitic Lightweight Ductile Iron Castings. AFS Trans. 2003, 111, 1149-1164.

7. Fragassa, C.; Minak, G.; Pavlovic, A. Tribological aspects of cast iron investigated via fracture toughness. Tribol. Ind. 2016, 38, 1-10.

8. Fras, E. Solidification of Metals; WNT: Warsaw, Poland, 2003; ISBN 83-204-2787-8.

9. Campbell, J. Castings; Butterworth-Heinemann: Oxford, UK, 1991.

10. Jincheng, L.; Elliot, R. The influence of cast structure on the austempering of ductile iron. Int. J. Cast Met. Res. 1999, 11, 407-411.

11. Fraś, E.; Górny, M.; Lopez, H.F. Chilling Tendency and Nodule Count in Ductile Cast Iron Part II-Experimental Verification. AFS Trans. 2006, 114, 595-603.

12. Fraś, E.; Górny, M.; Lopez, H.F. The Transition from Gray to White Iron during Solidification, Part I-Theoretical Background. Metall. Mater. Trans. A 2005, 36A, 3075-3082. [CrossRef] 
13. Lesoult, G.; Castro, M.; Lacaze, J. Solidification of Spheroidal Graphite Cast Iron: III Microsegregation Related Effects. Acta Mater. 1999, 47, 3779-3792.

14. Rebasa, N.; Dommarco, R.; Sikora, J. Wear Resistance of High Nodule Count Ductile Iron. Wear 2002, 253, 855-861. [CrossRef]

15. Stefanescu, D.M.; Alonso, G.; Larranaga, P.; De la Fuente, E.; Suarez, R. A Comparative Study of Graphite Growth in Cast Iron and in Analogous Systems. Int. J. Metalcast. 2018, 1-31. [CrossRef]

16. Stefanescu, D.M.; Alonso, G.; Larranaga, P.; De la Fuente, E.; Suarez, R. On the crystallization of graphite from liquid iron-carbon-silicon melts. Acta Mater. 2016, 107, 102-126. [CrossRef]

17. Lacaze, J. Trace Elements and Graphite Shape Degeneracy in Nodular Graphite Cast Irons. Int. J. Metalcast. 2016, 11, 44-51. [CrossRef]

18. Guo, J.; Samonds, M.T. Modeling and Experimental Validation of Ductile Iron Castings During Solidification. J. Mater. Eng. Perform. 2008, 17, 831-837. [CrossRef]

19. Stefanescu, D.M. Solidification and modeling of cast iron-A short history of the defining moments. Mat. Sci. Eng. A Struct. 2005, 413, 322-333. [CrossRef]

20. Beltran-Sanchez, L.; Stefanescu, D.M. Growth of solutal dendrites: A cellular automaton model and its quantitative capabilities. Metall. Mater. Trans. A 2003, 34, 367-382. [CrossRef]

21. Beltran-Sanchez, L.; Stefanescu, D.M. A quantitative dendrite growth model and analysis of stability concepts. Metall. Mater. Trans. A 2004, 35, 2471-2485. [CrossRef]

22. Wang, W.; Lee, P.D.; Mclean, M. A model of solidification microstructures in nickel-based superalloys: Predicting primary dendrite spacing selection. Acta Mater. 2003, 51, 2971-2987. [CrossRef]

23. Zhu, M.; Zhang, L.; Zhao, H. Modelling of microstructural evolution during divorced eutectic solidification of spheroidal graphite irons. Acta Mater. 2015, 84, 413-425. [CrossRef]

24. Wu, B.; Meng, D.; Zheng, H.; Tian, X. Numerical simulation of microstructure evolution on near eutectic spheroidal graphite cast iron. China Foundry 2017, 14, 386-391. [CrossRef]

25. Ruxanda, R.; Beltran-Sanchez, L.; Massone, J.; Stefanescu, D.M. On the Eutectic Solidification of Spheroidal Graphite Iron-An Experimental and Mathematical Modeling Approach. AFS Trans. 2001, 109, 1037-1048.

26. Fraś, E. Theoretical background of inoculation: Part I: Metals and single phase alloys. Arch. Foundry Eng. 2010, 12, 89-96.

27. Pan, E.N.; Hsu, W.S.; Loper, J.C.R. Effects of Some Variables on the Matrix and Mechanical Properties of Ferritic Ductile Irons. AFS Trans. 1988, 96, 645-660.

28. Qing, J.; Richards, V.L.; Van Aken, D.C. Examination of Austenite Solidification and Spheroidal Graphite Growth in Ni-Fe-C Alloys. In Advances in the Science and Engineering of Casting Solidification; Springer: Cham, Switzerland, 2015; pp. 277-288, ISBN 978-3-319-48117-3.

29. Rivera, G.; Boeri, R.; Sikora, J. Revealing and characterising solidification structure of ductile cast iron. Mater. Sci. Technol. 2002, 18, 691-697. [CrossRef]

30. Rivera, G.; Calvillo, P.R.; Boeri, R.; Houbaert, Y.; Sikora, J. Examination of the solidification macrostructure of spheroidal and flake graphite cast irons using DAAS and ESBD. Mater. Charact. 2008, 59, 1342-1348. [CrossRef]

31. Rivera, G.; Boeri, R.; Sikora, J. Searching for a Unified Explanation of the Solidification of Cast Irons. In Proceedings of the 8th International Symposium on Science and Processing of Cast Iron, Beijing, China, 16-19 October 2006; pp. 45-50.

32. López, M.; Rivera, G.; Massone, J.; Boeri, R. Solidification Macrostructure of Compacted Graphite Cast Iron and its relationship with Shrinkage Porosity. In Proceedings of the 10th International Symposium on the Science and Processing of Cast Iron, Mar del Plata, Argentina, November 2014. Available online: http:/ / rinfi.fi.mdp.edu.ar/xmlui/handle/123456789/51 (accessed on 10 May 2018).

33. Kopyciński, D.; Guzik, E.; Szczęsny, A.; Dorula, J.; Siekaniec, D.; Ronduda, M. Inoculation of Austenite Primary Grains in Cast Iron. Arch. Foundry Eng. 2014, 14, 45-48. [CrossRef]

34. Elmquist, L.; Diószegi, A.; Svidró, P. Influence of Primary Austenite on the Nucleation of Eutectic Cells. Key Eng. Mater. 2011, 457, 61-66. [CrossRef]

35. Natxiondo, A.; Suárez, R.; Sertucha, J.; Larrañaga, P. Graphite and Solid Fraction Evolutions during Solidification of Nodular Cast Irons. Metals 2015, 5, 239-255. [CrossRef] 
36. Fatahalla, N.; AbuElEzz, A.; Semeida, M. C, Si and Ni as alloying elements to vary carbon equivalent of austenitic ductile cast iron: Microstructure and mechanical properties. Mater. Sci. Eng. A 2009, 504, 81-89. [CrossRef]

37. Górny, M.; Kawalec, M.; Sikora, G.; Lopez, H.F. Effect of Cooling Rate and Titanium Additions on Microstructure of Thin-Walled Compacted Graphite Iron Castings. ISIJ Int. 2014, 54, 2288-2293. [CrossRef]

38. Llorca-Isern, N.; Nesa, D.; Vicente, M. Thin wall compacted graphite cast iron for automotive applications. Int. J. Cast. Metal. Res. 2003, 16, 325-328. [CrossRef]

39. Dawson, S.; Schroeder, T. Practical applications for compacted graphite iron. AFS Trans. 2004, 114, 1-9.

40. Guesser, W.; Schroeder, T.; Dawson, S. Production experience with compacted graphite iron automotive components. AFS Trans. 2001, 109, 1-11.

41. Fraś, E.; Górny, M. Fading of inoculation effects in ductile iron. Arch. Foundry Eng. 2008, 8, 83-87.

42. Zhou, J. Colour metallography of cast iron. Grey Iron II. China Foundry 2009, 6, 255-267.

43. Podrzucki, C.; Wojtysiak, A. Unalloyed ductile iron. Part I-Cast iron with spheroidal graphite; AGH: Crakow, Poland, 1987; pp. 85-124.

44. Fraś, E.; Górny, M.; Lopez, H.F. Eutectic Cell and Nodule Count in Cast Iron Part I. Theoretical Background. ISIJ Int. 2007, 47, 259-268. [CrossRef]

45. Yeung, C.F.; Zhao, H.; Lee, W.B. The Morphology of Solidification of Thin-Section Ductile Iron Castings. Mater. Charact. 1998, 40, 201-208. [CrossRef]

46. Stefanescu, D.M. Science and Engineering of Casting Solidification, 3rd ed.; Springer: Cham, Switzerland, 2015; ISBN 978-3-319-15692-7.

47. Boeri, R.; Sikora, J. Solidification macrostructure of spheroidal graphite cast iron. J. Cast Met. Res. 2001, 13, 307-313. [CrossRef]

48. Stefanescu, D.M.; Dhindaw, B.K.; Kacar, S.A.; Moitra, A. Behavior of ceramic particles at the solid-liquid metal interface in metal matrix composites. Metall. Mater. Trans. A 1988, 19, 2847-2855. [CrossRef]

(C) 2018 by the authors. Licensee MDPI, Basel, Switzerland. This article is an open access article distributed under the terms and conditions of the Creative Commons Attribution (CC BY) license (http:/ / creativecommons.org/licenses/by/4.0/). 